\title{
Reconstruindo a parede abdominal: o advento de uma técnica
}

\section{Rebuilding the abdominal wall: the birth of a technical}

TCBC Renato Miranda de Melo'

\section{INTRODUÇÃO}

O eminente cirurgião e professor, João Baptista de Resende Alves, então à frente da Cátedra de Técnica Operatória na Faculdade de Medicina da Universidade de Minas Gerais, seguramente tinha à sua disposição um séquito de jovens médicos, ávidos por obterem treinamento cirúrgico com o grande mestre e seus colaboradores. A Faculdade de Medicina de Belo Horizonte foi fundada em 1911, como escola isolada de ensino superior. Em 1927, foi reunida a outras três (Direito, Odontologia e Engenharia) para constituírem a Universidade de Minas Gerais, instituição privada, porém subsidiada pelo Estado. Em 1949, foi federalizada, e já contava com outros cursos (Arquitetura, Filosofia e Ciências Econômicas), mas o nome Universidade Federal de Minas Gerais/UFMG somente foi incorporado em 1965. A Reforma Universitária de 1968 extinguiu a Cátedra e instituiu a departamentalização na universidade brasileira ${ }^{1}$.

Entre os colaboradores do Prof. João Baptista de Resende Alves, destacava-se, por sua força de trabalho e abnegação, o cirurgião geral Alcino Lázaro da Silva (Figura 1), seu assistente mais dedicado. Natural de Guaranésia, uma pequena cidade situada no Sul de Minas, diplomouse em 1959, na mesma faculdade onde se desdobrava para atender à demanda infindável de pacientes e de alunos que acorriam àquele serviço, instalado no Hospital da Cruz Vermelha.

Por sugestão do Prof. Resende Alves, Alcino assumiu o atendimento médico do Hospital Cassiano Campolina (Figura 2), na cidade de Entre Rios de Minas. Localizada $110 \mathrm{~km}$ ao sul da capital mineira, próximo a São João Del Rei, exatamente entre os rios Brumado e Camapuã. Foi nesta cidade também que nasceu e atuou o Prof. Resende Alves.

Também em Entre Rios vivia Cassiano Antônio da Silva Campolina, descendente de imigrantes portugueses. Ele nunca se casou nem teve filhos. Esse próspero e benemerente fazendeiro muito fez por seus concidadãos: legou sua fortuna para a construção de um hospital, cuja pedra fundamental sequer viu lançada, infelizmente, pois faleceu dois anos antes. Em seu primeiro testamento, Cassiano Campolina deixava sua herança para os amigos Joaquim Pacheco de Resende e João Ribeiro de Oliveira,

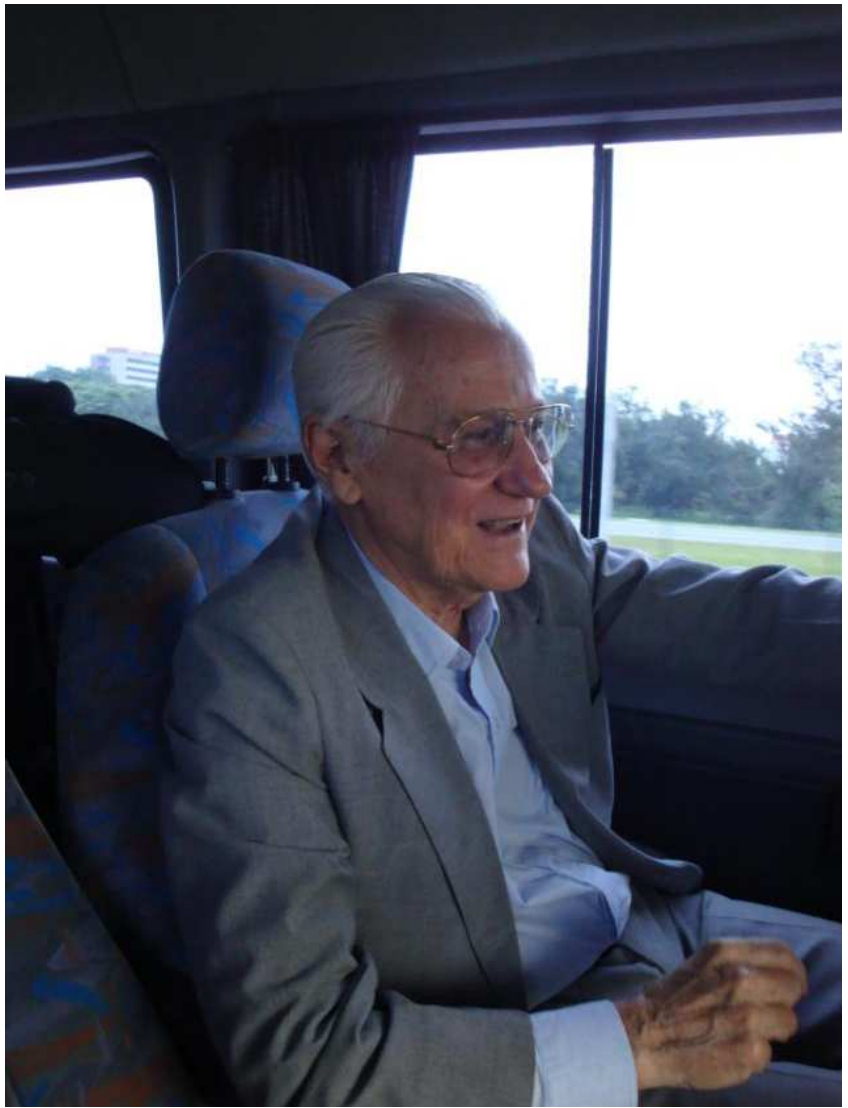

Figura 1 - Alcino Lázaro da Silva na viagem para Botucatu/SP em 25/10/2009 (foto de Renato M. Melo).

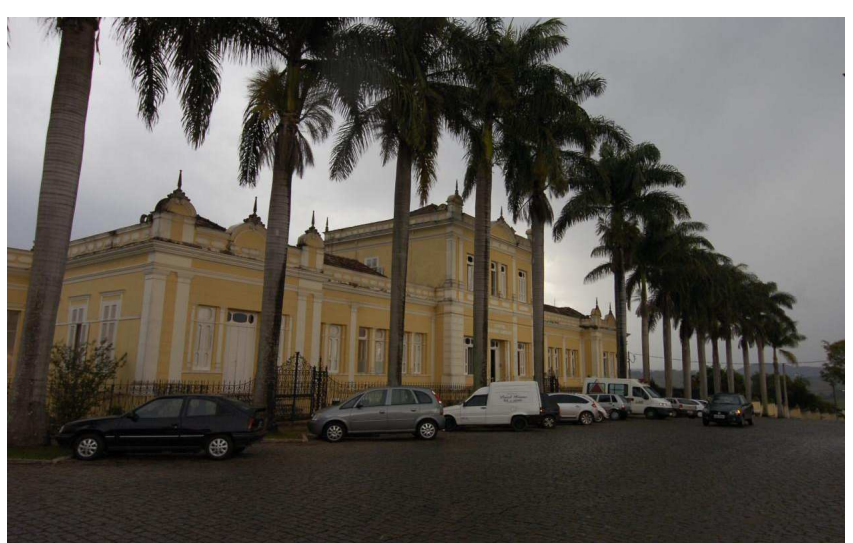

Figura 2 - Hospital Cassiano Campolina - HCC, Entre Rios de Minas/MG (foto de Renato Weil).

1. Professor Adjunto do Departamento de Cirurgia da FM-UFG. Coordenador do Serviço de Parede Abdominal da Santa Casa/PUC-GO Goiânia, GO. 
que prontamente abdicaram da oferta em prol da construção do hospital. Diante disso, o testamento foi refeito. Meritoriamente, o hospital leva o seu nome e mantém suas portas abertas à população, local e regional, desde que foi inaugurado, há exatos 100 anos $^{2}$.

Nele, Alcino trabalharia de domingo à sexta-feira, atendendo e operando todos que dele necessitassem, sem descanso nem distinção, como sempre foi do seu feitio. Dois colegas o ajudavam nas operações: nos primeiros anos, Antônio Guimarães, e no final, Paulo Silva. As anestesias, quando inalatórias, ficavam por conta do Sr. Antônio Pedro da Silva, enfermeiro prático, mas que manipulava, como poucos, a máscara de Ombrédanne. Muito bem-treinado pelo Prof. Resende Alves, nos anos em que atuou no Hospital Cassiano Campolina, ele administrava o éter em sincronia britânica com o desenrolar da operação. Ao despertar o paciente, comentava: "Comportou muito bem!" Dia após dia, sua postura sempre gentil, porém firme, reafirmava a confiança daquele jovem cirurgião em seu fiel ajudante. Não há registro de complicações relacionadas às anestesias praticadas pelo Sr. Antônio Pedro ${ }^{3}$.

Nos finais de semana, Alcino retornava ao serviço do Prof. Resende Alves, para dedicar-se ao trabalho acadêmico, que era ou sempre fora o seu objetivo maior. Esse ir e vir estendeu-se de 6 de janeiro de 1960 até julho de 1966, quando passou a frequentar cada vez mais a capital, até desligar-se completamente de Entre Rios. Antes disso, providenciou para que outro colega assumisse o seu lugar, e só então regressou definitivamente para Belo Horizonte, onde vive e trabalha até hoje.

Mas a vocação de Entre Rios não ficaria restrita somente por suas inegáveis contribuições à Cirurgia Geral e do Aparelho Digestivo ou ao Ensino Médico, que aquele cirurgião, no início de uma carreira brilhante, se notabilizaria. O futuro reservava um lugar de destaque ao idealizador de um procedimento, que se tornaria amplamente reconhecido por sua efetividade no tratamento da hérnia incisional.

E o que é uma hérnia incisional ou eventração? É a protrusão do conteúdo peritonial através de uma cicatriz enfraquecida na parede do abdome. Ela se torna abaulada quando o paciente fica de pé ou realiza algum esforço físico. Para corrigi-la, é necessário cobrir o defeito, seja com os próprios tecidos do paciente ou utilizando uma prótese (tela), sem gerar tensão excessiva na linha de sutura nem no interior da cavidade peritonial.

Essa história tem início graças ao inconformismo de nosso jovem e contumaz cirurgião, frente às parcas opções de tratamento das eventrações naquela época. Se já eram incomuns os resultados favoráveis com os reparos teciduais, o que dizer então das telas? Raras e dispendiosas, nem por isso eram tão extraordinárias: infecção, rejeição, extrusão e fragmentação constituíam verdadeiros tormentos, e longe de serem raros. O polipropileno das revolucionárias telas de Márlex acabava de ser lançado na América do Norte, e por lá ficaria ainda durante muito tempo. Como prestar socorro efetivo, então, aos pacientes rendidos, muitos deles alijados do convívio social, sem oportunidade de trabalho, e que depositavam naquele médico do Hospital Cassiano Campolina sua derradeira esperança de cura? A melhor saída, e talvez a única, fosse improvisar; fazendo uso obviamente de uma sólida formação cirúrgica, mas, ainda assim, improvisar...

Embora condoído, Alcino fazia do desafio sua motivação para prosseguir. Já que não poderia contar com as próteses - ainda bem, pois a presença de um "corpo estranho", mesmo que por beneficência, o incomodava também o incomodava desconsiderar a anatomia, isto é, não refazê-la durante o reparo da parede. "O destino do saco herniário não poderia continuar sendo o balde da sala operatória: um tecido autógeno, resistente, eutérmico, prontamente disponível e, quanto maior ele fosse, melhor !" Estava ali a sua prótese tão desejada, mas não bastava isso. Era fundamental fechar o defeito, o que significava reaproximar os músculos retos do abdome, afastados pela hérnia, para a sua posição original, ou seja, recompor a linha alba. Fazer isso sem gerar tensão excessiva exigiria fartas incisões relaxadoras. Isso já era conhecido e adotado. Todavia, essas mesmas incisões deixavam os retos desnudos, o que poderia comprometer a sua eficiência durante a contração da parede. Daí o saco herniário, para recobrilos. Por que não?

Ainda que confinada na mente do seu criador, ia-se delineando a proposta de uma reconstrução completa da parede abdominal (anatômica e fisiológica).

O atendimento e as operações se sucediam. Quaisquer que fossem, Alcino aproveitava para revisar a anatomia da parede, ensaiar alguns passos, amadurecer as hipóteses e reiterar as convicções. "Liberação dos retos para cá; criação de retalhos para lá; e no meio o que fazer com eles?" Bom mineiro que sempre foi, silente e precavido ia criando a coragem necessária para pôr em prática o seu projeto, no momento oportuno, sem percalços. Algumas ideias geniais acontecem de estalo; outras, ao contrário, são gestadas mais demoradamente.

Como todo cirurgião de seu tempo, cabia-lhe também praticar a ginecologia-obstetrícia. Em 23 de fevereiro de 1965, uma senhora com 28 anos de idade, portadora de mioma uterino e hérnia incisional mediana infraumbilical, foi internada aos seus cuidados e ali permaneceria até o dia 11 de março. Era a oportunidade para executar o seu engenho (ou parte dele), que já nascia ante a perspectiva da realização de procedimentos associados ou conjuntos ao reparo da parede. Auxiliado pelo Dr. Paulo e pelo Sr. Antônio, com sua inseparável máscara de Ombrédanne, a operação ficou agendada para um histórico $1^{\circ}$ de março de 1965 . Sob anestesia geral, na qual também se utilizou Gardenal ${ }^{\circledR}$ e Fenergan ${ }^{\circledR}$, ela foi descrita assim: "Incisão mediana infra-umbilical. Histerectomia subtotal. Salpingectomia. Fixação dos ovários na brecha da peritonização. Tecidos ainda frouxos, de puerpério normal. Apendicectomia (retro-cecal descendente). Salpingite (?) 
à direita. Hidátide direita grande (azeitona). Vesícula longa, sem cálculo, mas com o fundo torcido, dando ao conjunto a forma de S itálico, sobre o eixo da vesícula. Plástica da parede: jaquetão do peritônio; pontos separados nos retos aproximando-os e jaquetão da aponeurose. Fio categute. Dreno. Dieta líquida. Dreno no $2^{\circ}$ dia. Pontos no $8^{\circ}$ dia. Bem. 1977 maio."

Há um esboço na ficha que mostra os músculos retos do abdome afastados do plano mediano e, em seguida, reunidos por sutura interrompida.

Nascia a primeira versão daquela que seria a transposição peritônio-aponeurótica longitudinal bilateral (TRANSPALB).

Um ano antes, em 12 de julho de 1964, uma cesariana traria à luz não apenas mais um entrerriano, mas também outra oportunidade para reiterar a nova e promissora técnica de reparo das hérnias incisionais. A supuração da ferida operatória, ainda comum naquela época, foi devidamente tratada, mas sobreveio a eventração. $\mathrm{O}$ incômodo fez a paciente retornar quase dois anos depois, com hérnia incisional de tamanho médio, localizada na linha mediana infraumbilical. Em 15 de abril de 1966, três meses antes de deixar Entre Rios, Alcino perpetrou aquele mesmo procedimento na parede, só que agora estava ainda mais convicto e firme em seu propósito, pois o realizaria de maneira exclusiva. Prepararam-Ihe a paciente, novamente convocou o Dr. Paulo, para auxiliá-lo, e o Sr. Antônio, para anestesiá-la (sempre da mesma maneira e com as mesmas drogas), e puseram-se a operar. O arranjo, segundo seu próprio relato, constou de: (Incisão) " infraumbilical mediana. Dissecção da eventração. Jaquetão do peritônio. Exposição dos retos abdominais. Pontos separados, aproximando-os. Jaquetão da aponeurose anterior dos retos. Fio categute. Dreno."

Essas duas descrições, embora bastante sumárias, não reproduzem o arranjo ultimado para a proposta técnica. Primeiro não ficou claro de que maneira ou com que estruturas foi realizado o "jaquetão das aponeuroses" - se com os lábios laterais ou com os mediais das bainhas fendidas, ambas anteriormente. É provável que tenha sido com essas últimas, do contrário, Alcino não se incomodaria tanto em deixar os músculos retos desnudos, além do que a sutura dos lábios laterais aumentaria muito a pressão intra-abdominal e a tensão na linha de sutura. Em segundo lugar, ainda faltavam as incisões relaxadoras na bainha dos músculos retos do abdome, anterior de um lado e posterior do outro. Os seus folhetos laterais receberiam os do saco herniário fendido (hemissacos), para serem reconstituídas imediatamente.

A primeira série com 15 casos foi publicada na extinta revista "O Hospital" ${ }^{4}$. As ilustrações, feitas à mão livre pelo autor, mostram também a imbricação dos folhetos na reconstituição da bainha dos músculos retos do abdome, como alternativa à sutura lábio a lábio dos mesmos (Figuras 3 e 4).
Entre as desvantagens da técnica, o autor cita o "período pequeno de observação (máximo de três anos para a mais antiga) ". Uma vez que a publicação ocorreu no primeiro número do volume 79 da revista, em janeiro de 1971, certamente o artigo fora escrito no ano anterior, isto é, em 1970. Assim, a primeira transposição completa, referida no artigo inaugural, fora realizada de fato em 1967.

Em seguida, ampliaram-se as indicações, para que as diástases e as hérnias umbilicais volumosas também fossem corrigidas pela TRANSPALB. Essa experiência acumulada (55 pacientes operados) veio à público no primeiro volume da Revista do Colégio Brasileiro de Cirurgiões ${ }^{5}$, na qual o autor menciona que "o mais antigo foi há nove anos", o que nos remete a 1965. Mais uma vez, como a publicação se deu no terceiro número da revista (maio-junho), o artigo deve ter sido entregue no mês de março ou, no mais tardar, em abril. Se assim se deu, a análise feita pelo autor encerrou-se em fevereiro de 1974, provavelmente, do que resulta o paciente mais antigo ter sido operado em 1965, e não em 1967.

As descrições nas fichas das pacientes operadas em 1965 e 1966 não retratam a TRANSPALB, mas apenas parte dela, como se viu. Portanto, a menção ao primeiro paciente, neste segundo artigo, talvez tenha sido equivocada, e o procedimento completo foi realizado em 1967 mesmo, quando Alcino já havia se transferido definitivamente para a capital mineira.

\section{Plástica com o saco herniário na correção das hérnias incisionais}

\section{ALCiNo lazaro da Silva (1)}

\section{JUSTIFICATIVA}

Apresentamos uma plástica com o saco herniário, na correção das Eventrações ou Hérnias Incisionais (HI) medianas e ânterolaterais.

Justifica-se através de: a) estudo da dinâmica abdominal; b) a HI é uma patologia acessivel a todo cirurgião geral, neófito ou experimentado, do grande centro ou do interior; c) é uma hernia freqüente; d) apresenta muitas recidivas, näc obstante múltiplas técnicas para surestão: muitas técnicas são complicada teilicadas (a) material de prótese, porque não se encontra no Brasil ou por ser de alto

Após ter praticado a operação em alguns pacientes, verificamos que parece não existir proposta similar na literatura. Nas publicações de Romano (1940) e Berman (1945) encontramos alguns pontos em comum.

\section{GINERALIDADES}

Dentre os princípios fundamentais na correção cirúrgica da HT podemos enumerar os que seguem $(1,2,7,8,20)$.

1) Suturar tecidos de mesma natureza;

2) A reparação deve ser por planos;

3) Não incluir entre as suturas tecidos muscular, adiposo ou picatricial;

(1) Professor Assistente do Departamento de Cirurgia da Fac. Med. U.F.M.G., Servlço do Pıof. Resende Alves.

$$
-129-
$$

Figura 3 - Fac-símile da página inicial do trabalho inaugural sobre a TRANSPALB, publicado na revista "O Hospital" em 1971. 

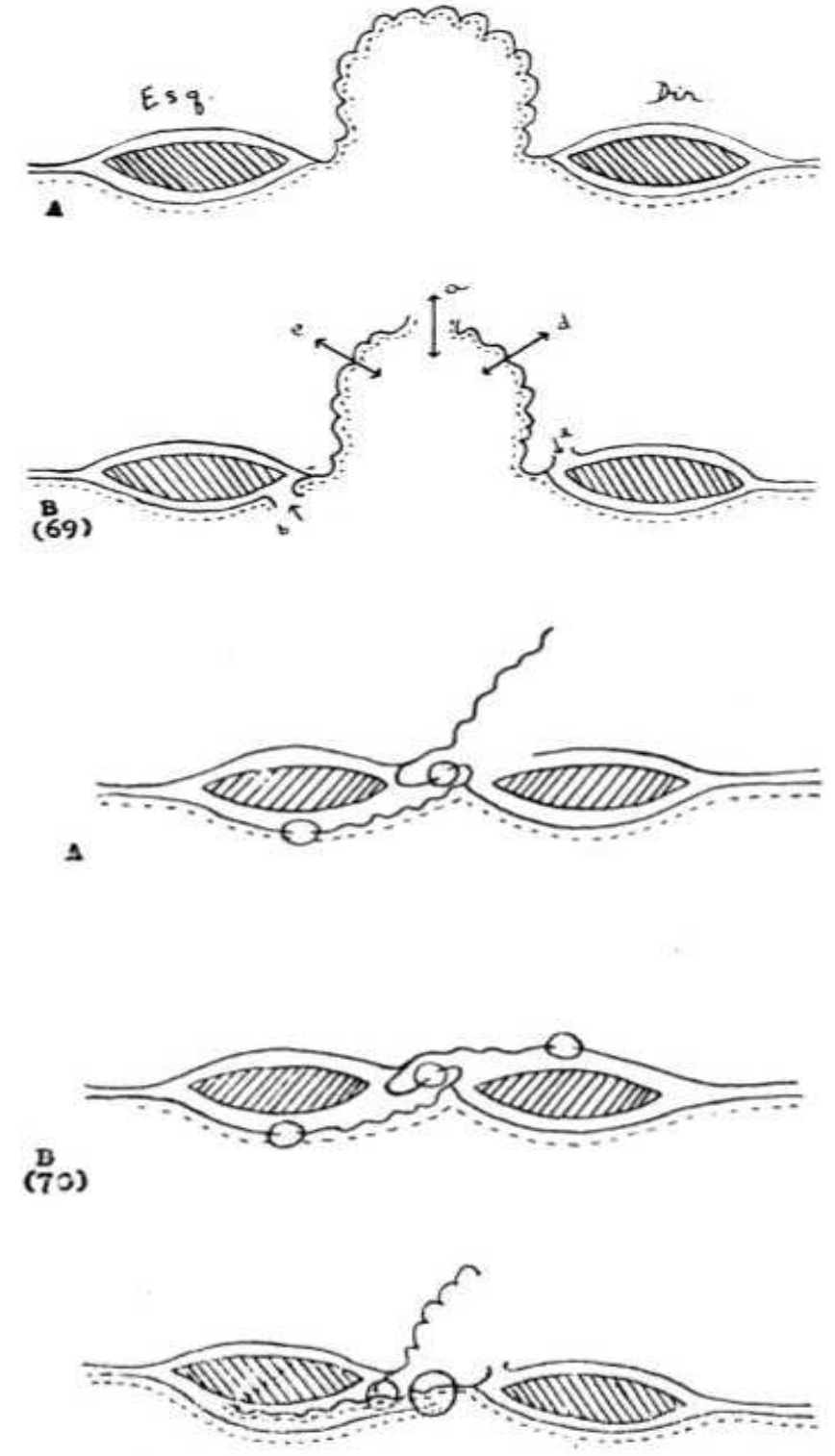

$\mathbf{A}$

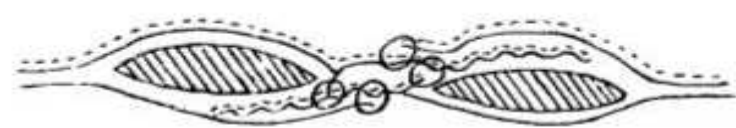

\section{$(723)$}

Figura 4 - $\quad$ llustrações do artigo sobre TRANSPALB, publicado na Revista "O Hospital" em 1971.

Assim, em 11 de janeiro de 1967 a primeira TRANSPALB parece ter sido praticada integralmente, ou quase (Figura 5). É o relato mais antigo que o próprio Alcino, revendo todos os seus prontuários, pessoalmente, conseguiu recuperar. O paciente era um lavrador, solteiro, com 23 anos de idade. Seis meses antes, fora vítima de ferimento por arma branca no abdome, que o levou ao choque hemorrágico por lesão renal. Submetido à nefrectomia esquerda, através de incisão mediana xifopúbica, a ferida abdominal infectou-se e, por fim, abriu-se completamente. A eventração que se desenvolveu foi assim reparada na ficha n 4188:" Laparotomia, ressecando a cicatriz. Dissecção do retalho de pele. Dissecção do peritônio e aponeurose posterior dos retos. Dissecção dos retos. Dissecção da aponeurose anterior. Sutura por planos. A anterior ficou tracionada. Dreno "

Essa descrição, bastante sumária, não aponta como os folhetos foram aproximados na "sutura por planos". Ela foi corroborada por outra, datada de 9 de novembro de 1968, tão sintética quanto as demais, porém bem mais detalhada e acompanhada do primeiro esboço (Figura 6). Ambas representam um claro avanço em relação à proposta de 1965 e 1966. Em 1968, era um paciente masculino, de 72 anos, lavrador, com eventração póscolecistectomia. No cabeçalho da ficha operatória ( $\left.n^{\circ} 4290\right)$ consta "Hérnia Incisional - Correção Minha": "Incisão mediana, long. supra-umbilical. Abertura do peritônio. Alça aderida. Ex(...)ação. Ressecção $\pm 20 \mathrm{~cm}$. A $1 / 2$ esq do peritônio estava livre. A dir. tinha aderências devido à colecistectomia anterior. Incisão no folheto post. do reto esq. Sutura do lábio dir. do saco herniário ao lábio lateral da secção. Sutura do lábio medial desta sobre o retalho dir. do saco. Sutura do retalho esq. do saco ao lábio lateral da ap. ant. do reto seccionada longitudinalmente. Categute. Dreno. Cinta elástica por três meses."

Estava delineada a TRANSPALB, embora a sutura dos lábios mediais das lâminas anterior e posterior, fendidas na bainha dos retos e que faria parte do arranjo final, perdeu-se no tempo.

Desde o início, utilizava o categute em pontos separados. O próprio autor enfatiza isso, até hoje, embora tenha feito referência à sutura contínua em seu primeiro artigo, ao elencar os princípios fundamentais na correção das hérnias incisionais. Uma vez que a síntese dos planos era realizada sem tensão excessiva, percebeu que poderia dispensar também os fios inabsorvíveis, que provocavam os indesejáveis granulomas piogênicos. Além do mais, o categute era e ainda é facilmente encontrado em qualquer hospital, do mais simples ao mais sofisticado.

Já consagrada no Brasil, a técnica ganhou projeção internacional", na conceituada "Surgery, Gynecology \& Obstetrics" (continuada como "Journal of the American College of Surgeons"), tornando-se a principal referência à TRANSPALB.

As pesquisas, na década de 70, estenderam-se inevitavelmente ao laboratório, a fim de demonstrar o rearranjo da parede, obtido com a transposição. Essa e outras contribuições também vieram por iniciativa do próprio Alcino, que instalou a Pós-Graduação em Cirurgia na FM-UFMG em 1972. A primeira tese, na qual se conseguiu reproduzir experimentalmente a hérnia incisional mediana e também a TRANSPALB, foi desenvolvida no cão e defendida pelo mestrando Manoel Luiz da Silva Cataldo, sob a 


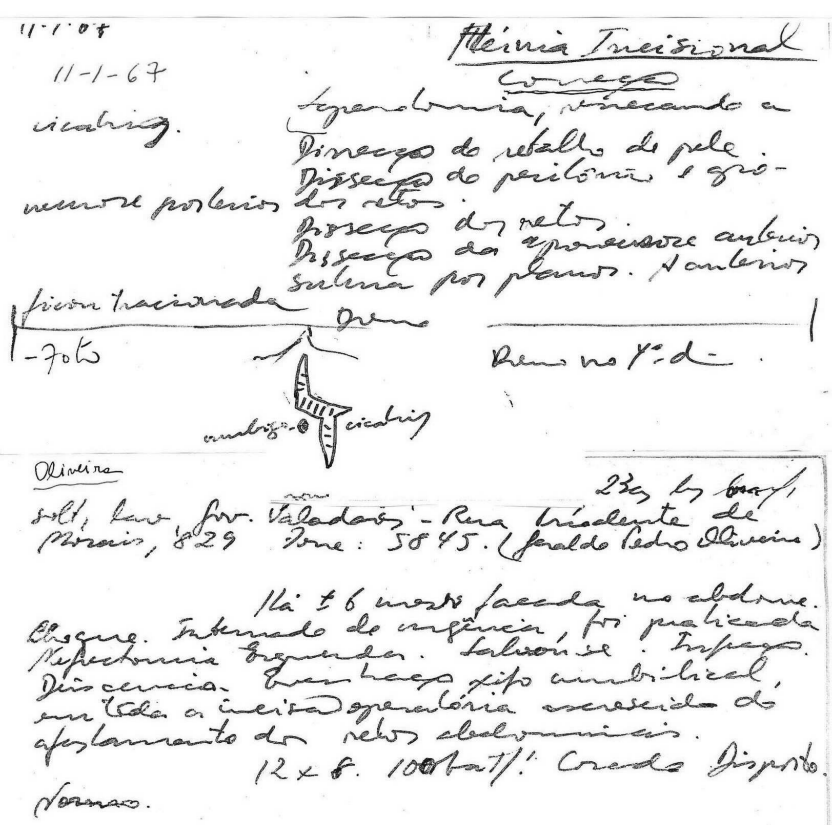

Figura 5 - Fac-símile da ficha referente à primeira operação realizada pelo Prof. Alcino, em 1967, na qual descreve o arranjo básico, mas não definitivo, da TRANSPALB.

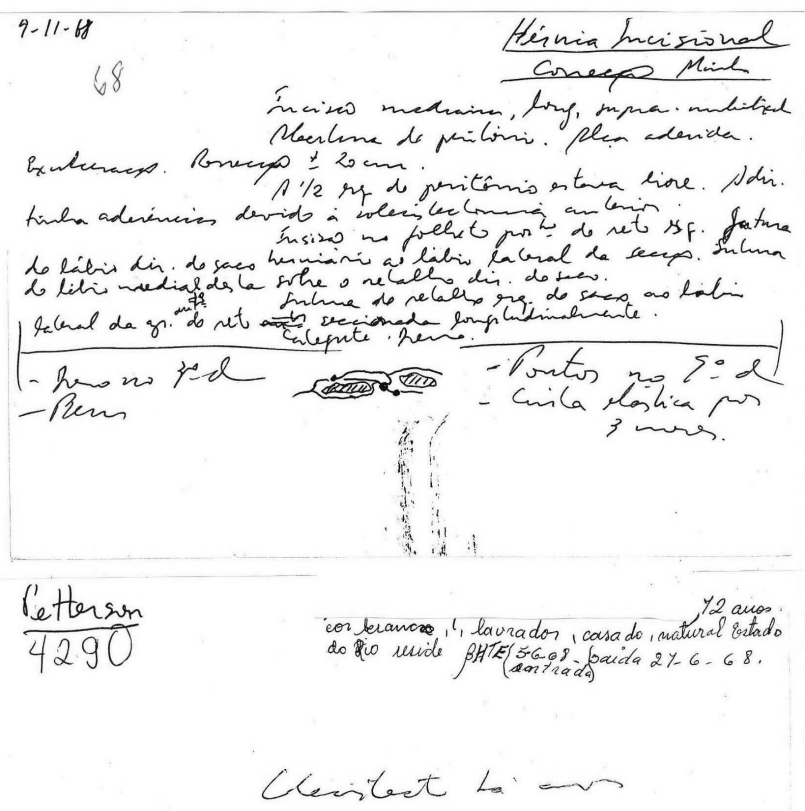

Figura 6 - Fac-símile da ficha referente a outra operação realizada pelo Prof. Alcino, em 1968, na qual descreve com mais pormenores o arranjo até então proposto da TRANSPALB.

orientação do Prof. Alcino e a colaboração de Alvino Jorge Guerra (Emprego do saco herniário na correção cirúrgica das hérnias incisionais longitudinais. Belo Horizonte, Faculdade de Medicina, UFMG, 1977). Com ela a demonstração inequívoca de que a técnica reconstruía completamente a parede abdominal. Alguns anos mais tarde, este trabaIho foi publicado na Revista do Colégio Brasileiro de Cirurgiões ${ }^{7}$.

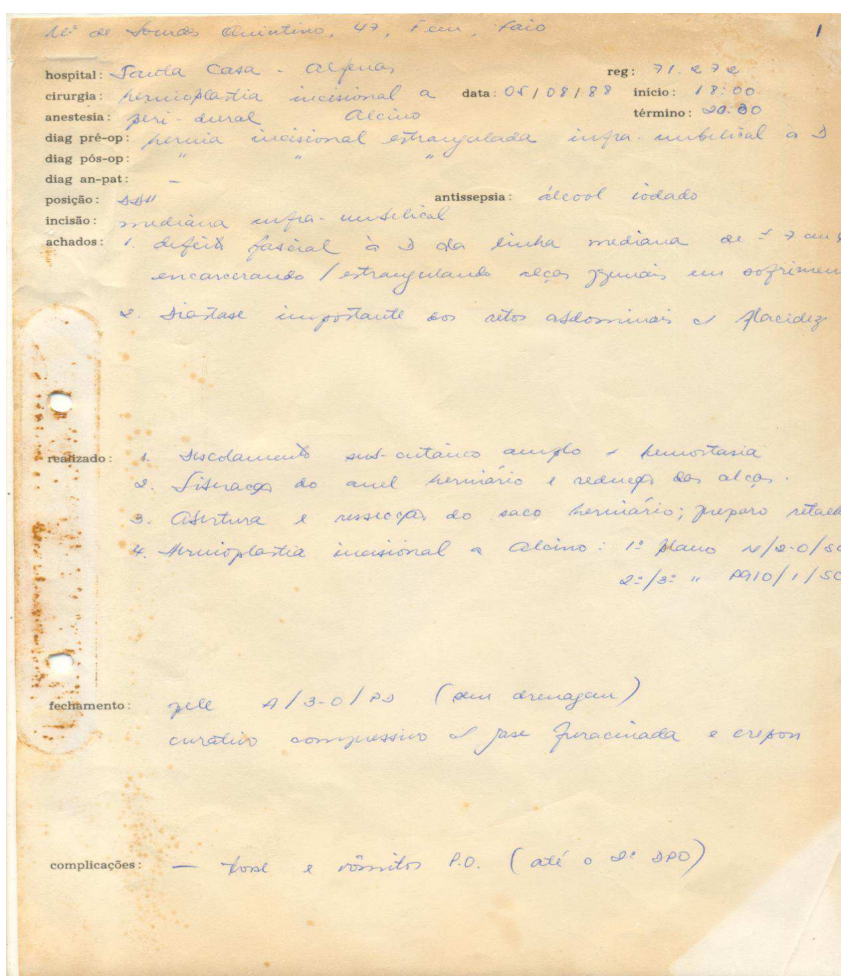

Figura 7 - $\quad$ Fac-símile da ficha referente à primeira operação realizada por mim (TRANSPALB), durante o período em que trabalhei na Casa de Caridade N. Sa. do Perpétuo Socorro, em Alfenas/MG.

Seguiram-se outros estudos, em especial os de Jorge Miguel Kather Netto, de Taubaté/SP (cálculo do volume do saco herniário), e os de Danilo Nagib Salomão Paulo8-11, de Vitória/ES (função respiratória e hérnia incisional). Além das séries de casos publicadas pelo próprio idealizador da técnica com outros colaboradores, há que destacar os trabalhos sobre a constituição do saco herniário ${ }^{12,13}$ realizados por Cirênio de Almeida Barbosa radicado em Belo Horizonte/MG. Todavia, nenhum ensaio clínico randomizado, adotando a TRANSPALB, foi publicado até o presente. Um ensaio desse tipo está sendo empreendido pelo autor deste relato histórico.

\section{CONSIDERAÇÕES FINAIS}

A simplicidade tem se mostrado o caminho mais curto para o sucesso, seja qual for o empreendimento. Soluções muito complexas costumam ser ou onerosas ou inviáveis. Um procedimento cirúrgico novo, por mais afoito que seja seu proponente, não surge da noite para o dia. Muito menos se consolida nesse lapso de tempo.

Refazer a parede abdominal, por qualquer meio, é laborioso, e o resultado nem sempre satisfaz ao paciente tampouco ao cirurgião. A versatilidade da TRANSPALB está na consecução de seu objetivo principal - restaurar a parede - e também no modo de fazê-lo. 
Minha identificação com esse procedimento surgiu quando eu ainda era estudante na Faculdade de Medicina da UFMG (1978 a 1983), em que a "técnica do Prof. Alcino" figurava como primeira escolha no tratamento das hérnias incisionais. Era difícil decifrá-la e, por isso mesmo, os professores riam-se enquanto debulhavam-na para nós. Pura fantasia, de ambas as partes, exacerbada pela quase idolatria que permeava a figura do Prof. Alcino. Sempre solícito, de fala mansa, quando nos via, detinha-se e abordava-nos pelo nome. Incrível! Não se esquecia de nenhum. Veio a formatura e logo o treinamento cirúrgico com Orestes Diniz Filho, em seu Hospital Santana, para quem "eventração era igual à técnica do Alcino", seu contemporâneo da Faculdade de Medicina.

Deixei Belo Horizonte e instalei-me no Sul de Minas, em Alfenas, onde permaneci 21 anos exercendo a Cirurgia Geral plenamente. Revendo os prontuários de minha clientela alfenense, encontrei a ficha da primeira paciente que operei, datada de 5 de agosto de 1988. Era uma hérnia incisional mediana infraumbilical corrigida pela TRANSPALB! (Figura 7). Coincidência? Conspiração universal? Sim e não. Outras se seguiram, e não foram poucas. Cada vez mais dedicado às hérnias, promovi algumas jornadas e frequentei diversas outras. Nelas, o Prof. Alcino era sempre o convidado de honra, com sua presença simples, porém marcante. Em 2003, reaproximei-me dele, agora para o doutorado, defendido no ano seguinte, sob

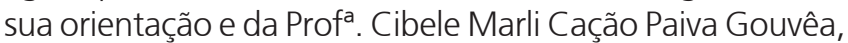
da Unifal-MG (Alfenas), quando estudamos a prevenção da hérnia incisional induzida experimentalmente.

Apesar dessa proximidade, nunca havia operado com o Prof. Alcino, sobretudo uma TRANSPALB, aluno que fora da sua escola, residindo no mesmo estado que ele e exercendo ambos a mesma especialidade médica. Essa lacuna seria preenchida em virtude do I Curso Teórico-Prático de Hérnia Inguinal e Incisional da Faculdade de Medicina de Botucatu-UNESP, organizado pelo amigo em comum José Guilherme Minossi. Era o dia 26 de outubro de 2009. Havia um caso de hérnia incisional reservado para eu operar, em princípio, mas diante da presença e disponibilidade do Prof. Alcino, inverti os papéis prontamente: ele, o cirurgião; eu e André Roma, os auxiliares (Figura 8). Sem pressa nem perda de tempo, "demoramos o necessário para fazer o necessário", como se já operássemos juntos por anos a fio. A graça enfim fora alcançada!

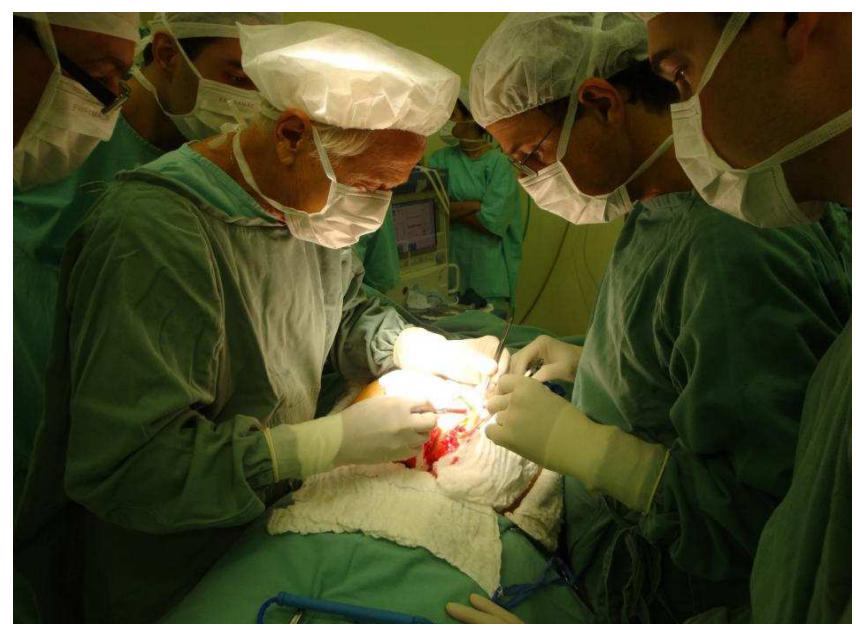

Figura 8 - $\quad$ TRANSPALB realizada por ocasião do I Curso TeóricoPrático de Hérnia Inguinal e Incisional da FM de Botucatu/UNESP/SP em 26/10/2009. Da esquerda para a direita: Prof. Alcino auxiliado por mim (RMM) e André Roma (foto de Cláudia N. Hajimoto).

Uma afecção como a hérnia incisional, que não respeita classe social nem limites geográficos, exige uma abordagem descomplicada, com recursos materiais comuns, para obter o alcance social desejável. Ou seja, qualquer proposta dessa natureza deve ser factível para o cirurgião, exequível para o hospital e sustentável para o sistema de saúde, além de eficaz naturalmente.

A TRANSPALB, ensaiada entre rios e estreada entre serras, preenche tais prerrogativas com maestria, e nisso reside a genialidade do seu criador.

\section{Agradecimentos}

Alcino Lázaro da Silva, cirurgião geral e do aparelho digestivo, Professor Emérito da UFMG, por ter idealizado a transposição peritônio-aponeurótica longitudinal bilateral - TRANSPALB. Resta-me prosseguir divulgando-a e, se possível, aprimorando-a, enquanto cirurgião geral, dedicado à parede abdominal, brasileiro e mineiro.

Joffre Marcondes de Rezende, gastroenterologista, Professor Emérito da UFG e Membro-Fundador da Sociedade Brasileira de História da Medicina, pela revisão dos originais e, especialmente, pela inspiração que me fez buscar, na história dos homens e seus feitos, as raízes da verdade e da justiça, quando bastaria mirar em seu exemplo de vida.

\section{REFERÊNCIAS}

1. UFMG . Disponível em http://www.ufmg.br/conheca. Acessado em 14/01/2010

2. Resende EO. Memorial Hospital Cassiano Campolina. Divinópolis: Sidil, 2000.

3. Resende Alves JCR. A cirurgia e o sonho: biografia de João Baptista de Resende Alves. Belo Horizonte: Artes Gráficas Formato, 2007.

4. Silva AL. Plástica com o saco herniário na correção das hérnias incisionais. O Hospital 1971;79:123-34.
5. Silva AL. Plástica com o saco herniário na correção das hérnias incisionais longitudinais, medianas ou para-retais e nas diástases dos retos abdominais. Rev Col Bras Cir 1974; 1(3):113-6.

6. Silva AL. Surgical correction of longitudinal median and paramedian incisional hernia. Surg Gynecol Obstet 1979;148:579-83.

7. Cataldo MLS, Silva AL, Guerra AJ. Emprego do saco herníário na correção cirúrgica das hérnias incisionais longitudinais: aspectos experimentais no cão. Rev Col Bras Cir. 1981;8(4):167-70. 
8. Paulo DNS, Silva AL, Paulo, ICAL, Rosalém G. Estudo da função respiratória em pacientes obesos e não obesos, com grandes hérnias incisionais. RBM - Revista Brasileira de Medicina. 1995;85(3):103-8

9. Paulo DNS, Silva AL. Repercussões respiratórias funcionais da hernioplastia incisional longitudinal abdominal. Rev Col Bras Cir. 1995; 22(1):33-42

10. Paulo DNS, Silva AL, Paulo ICAL. Hernioplastia incisional em paciente com doença pulmonar obstrutiva crônica grave. JBM. 1994; 67(5):111-16.

11. Paulo DNS, Silva AL, Paulo ICAL . Mobilidade diafragmática em pacientes com hérnia incisional abdominal longitudinal antes e após sua correção cirúrgica. RBM - Revista Brasileira de Medicina. 1994; 51(9): 1272-76.

12. Barbosa CA, Amaral VF, Silva A L. Histopatologia do saco herniário da hérnia inguinal indireta e do peritônio parietal em adultos e crianças: estudo qualitativo da sua musculatura lisa. Rev. Col. Bras. Cir. 2000; 27(3): 183-88.
13. Barbosa CA, Amaral VF, Silva AL. Histologia dos sacos herniários das hérnias inguinais indiretas, diretas, recidivadas e encarceradas em adultos e crianças: identificação de fibras musculares lisas. Rev. Col. Bras. Cir. 2002; 299(1):1-6.

Recebido em 18/08/2010

Aceito para publicação em 13/10/2010

Conflito de interesse: nenhum

Fonte de financiamento: nenhuma

\section{Como citar este artigo:}

Melo RM. Reconstruindo a parede abdominal: o advento de uma técnica. Rev Col Bras Cir. [periódico na Internet] 2010; 37(6). Disponível em URL: http://www.scielo.br/rcbc

Endereço para correspondência:

Renato Miranda de Melo

E-mail: dr.renatomelo@gmail.com 